\title{
COMPARISON OF BACK HANDSPRING TECHNIQUE PERFORMED BY ADVANCED ARTISTIC GYMNASTS - A CASE STUDY
}

\author{
JAROSŁAW OMORCZYK'1A, LESZEK NOSIADEK'1B, ROBERT STASZKIEWICZ1B, \\ PRZEMYSŁAW BUJASIC, EWA PUSZCZAŁOWSKA-LIZIS²
1University School of Physical Education in Kraków, Faculty of Physical Education and Sport, Department of Gymnastics and Dance ${ }^{a}$, Department of Biomechanics ${ }^{b}$, Department of Theory of Sport and Kinesiologyc 2University of Rzeszów, Faculty of Medicine, Institute of Physiotherapy

\author{
Mailing address: Jarosław Omorczyk, University School of Physical Education in Kraków, Department of \\ Gymnastics and Dance, 78 Jana Pawła II Ave., 31-571 Kraków, tel.: + 4812 6831337, fax: + 48 126831121, \\ e-mail: jaroslaw.omorczyk@awf.krakow.pl
}

\begin{abstract}
Introduction. The aim of this case study was to compare selected kinematic parameters that characterise the back handspring technique performed by advanced artistic gymnasts. Material and methods. Three elite gymnasts with varied training experience were examined in the study. The athletes performed back handsprings video-recorded at a frequency of $120 \mathrm{~Hz}$. The values of selected kinematic parameters were determined using SkillSpector v.1.3.2 computer software. Results. The most substantial differences between athletes were found in the values of the horizontal velocity of the centre of mass (CoM) at the end of the back handspring. The athlete with the longest training experience achieved values which were three times higher $(1.04 \mathrm{~m} / \mathrm{s})$ than those obtained by the other two athletes with shorter experience (Gymnast 2: $0.36 \mathrm{~m} / \mathrm{s}$; Gymnast 3: $0.37 \mathrm{~m} / \mathrm{s}$ ). The horizontal CoM velocity at the end of the back handspring declined for all the gymnasts, with the smallest decrease observed for the athlete with the longest training experience (two-fold decrease from 1.95 to $1.04 \mathrm{~m} / \mathrm{s}$ ) and the biggest one found for the athlete with the shortest training experience (six-fold decrease from 2.18 to $0.37 \mathrm{~m} / \mathrm{s}$ ). The vertical CoM velocity increased in all the athletes in the consecutive phases of the back handspring; this increase was the biggest for the athlete with the longest training experience (five-fold increase from 0.71 to $3.42 \mathrm{~m} / \mathrm{s}$ ) and the lowest for the athlete with the shortest training experience (three-fold increase from 1.08 to $3.24 \mathrm{~m} / \mathrm{s}$ ). Conclusions. The results obtained in this study demonstrated both similarities and substantial differences in the technique of performing the back handspring in artistic gymnasts with many years of training experience. In most cases, the directions of linear $\mathrm{CoM}$ velocities and angular velocities were similar in the joints analysed. Very similar values of angular positions were also obtained. Furthermore, the values which turned out to be the most varied were those recorded for angular velocity.
\end{abstract}

Key words: artistic gymnastics, back handspring, technique, kinematics

\section{Introduction}

In artistic gymnastics, attaining a high level of achievement involves the performance of many technically complex acrobatic elements. Learning to perform particularly challenging moves takes from several to more than ten years of training. The individual exercises learnt in this period are later refined through repetition and combination with other elements so that they can be incorporated into the routines performed during competitions.

One exercise which is of essential importance to artistic gymnastics is the back handspring. It belongs to the group of backward acrobatic moves [1], which are followed by a variety of acrobatic jumps [2,3]. Arkaev and Suchilin [4] indicate that for elite gymnasts, the back handspring is an element included in gymnastic warm-up routines (using basic acrobatic moves). The technique used for the performance of the back handspring should be learnt relatively quickly in order for athletes to be able to focus on much more challenging acrobatic elements. It can be assumed that longer training experience, which is conducive to improving the move, should also contribute to improving the repeatability and correctness of the exercises. As noted by re- searchers in other sports, more experienced athletes are characterised by improved repeatability when performing specific motor tasks [5, 6].

The technique of performing gymnastic exercises is affected by various factors, such as the athlete's training experience, somatic build, level of motor skills, and flexibility; the sports experience of the coach and their skills of verbal communication; and many others $[7,8,9]$. Learning, followed by regular work on the improvement of the acquired move, should involve regular verification of the performance level of each athlete. Apart from observation by coaches, detailed biomechanical analyses based on video recording are also utilised [10]. Such tools allow for a quantitative description of movement technique and a comparison between athletes based on the values of kinematic parameters obtained from the analysis.

The back handspring technique has been attracting much interest from researchers. One study [11] compared the results of a kinematic analysis of the back handspring performed by an acrobat and a ju-jitsu athlete. The authors focused on comparing the changes in the vertical position of the CoM in individual phases of the handspring and angular changes in selected joints of the lower and upper limbs. Penitente et al. [12] also carried 
out a kinematic analysis of the back handspring performed by artistic gymnastics athletes at various levels of performance.

The aim of this case study was to compare selected kinematic parameters that characterise the back handspring technique performed by advanced artistic gymnasts with varied training experience. Apart from the assessment commonly used by coaches (or judges), the achievement of the study aim was also supported by video recording, which, used together with the SkillSpector computer software, made it possible to perform biomechanical analyses. The authors attempted to answer the question of how the training experience of advanced gymnasts affects kinematic parameters and how much these parameters differ between athletes with varying training experience.

\section{Material and methods}

The examinations involved three elite athletes practising artistic gymnastics. The characteristics of the gymnasts are shown in Table 1. Each subject performed eight back handsprings (starting the move in a position with the arms stretched up), and the analysis was based on five items with the best level of technical performance. The technique was evaluated by three artistic gymnastics coaches who were also certified judges.

Table 1. Characteristics of the gymnasts

\begin{tabular}{|c|c|c|c|}
\hline Gymnast & $\begin{array}{c}\text { Training experience } \\
\text { (years) }\end{array}$ & $\begin{array}{c}\text { Height } \\
(\mathbf{c m})\end{array}$ & $\begin{array}{c}\text { Weight } \\
(\mathbf{k g})\end{array}$ \\
\hline G1 & 18 & 172.0 & 62.0 \\
\hline G2 & 16 & 173.0 & 63.2 \\
\hline G3 & 13 & 170.0 & 68.5 \\
\hline
\end{tabular}

The exercises were video-recorded at a frequency of $120 \mathrm{~Hz}$ using a Casio Exilim EX-FH25 digital camera. The values of selected kinematic parameters were determined using the 10-point two-dimension body model and SkillSpector v.1.3.2 computer software. These values were determined at nodal points (A, B, C, D, E, and F), i.e. at boundaries between each back handspring phase. The following phases of the back handspring were adopted (with their boundaries):

- first lower limb support phase (support on lower limbs; from A - beginning of arm swing - to B - taking toes off free exercise floor),

- first flight phase (from B to C - finger contact with free exercise floor),

- upper limb support phase (from C to D - taking fingers off free exercise floor),

- second flight phase (from D to E - toe contact with free exercise floor),
- second lower limb support phase (from E to F - taking fingers off free exercise floor).

The following kinematic parameters of the back handspring were determined:

- horizontal velocity of the centre of mass (CoM) [m/s],

- vertical velocity of the centre of mass $[\mathrm{m} / \mathrm{s}]$,

- angular position of the knee joint $\left[^{\circ}\right]$,

- angular position of the hip joint $\left[^{\circ}\right]$,

- angular position of the shoulder joint $\left[^{\circ}\right]$,

- angular velocity of the knee joint $[\% / s]$,

- angular velocity of the hip joint $[\% / s]$,

- angular velocity of the shoulder joint $[\% / \mathrm{s}]$.

Basic descriptive statistics were calculated, that is arithmetic means $(\overline{\mathrm{x}})$ and standard deviations (SD).

\section{Results}

Table 2 presents the horizontal and vertical velocities of the CoM at the boundaries between the back handspring phases.

At the moment of toe take-off (B) that completes the lower limb take-off phase, the gymnast with the shortest training experience (G3) obtained the highest CoM velocities in both the horizontal $(2.18 \mathrm{~m} / \mathrm{s})$ and vertical $(1.08 \mathrm{~m} / \mathrm{s})$ directions. However, at the moment adopted as the final point of the back handspring in this study $(F)$, the vertical velocity for this athlete rose (to $3.24 \mathrm{~m} / \mathrm{s}$ ), but it was lower than in the case of the other two athletes, whereas it decreased nearly six times in the horizontal direction (to $0.37 \mathrm{~m} / \mathrm{s}$ ). The highest values of the CoM velocities at the instant F were observed in the athlete Gl $(1.04 \mathrm{~m} / \mathrm{s}$ in the horizontal direction; $3.42 \mathrm{~m} / \mathrm{s}$ in the vertical direction). CoM horizontal velocities at the instant $\mathrm{F}$ for the gymnast $\mathrm{Gl}$ were substantially greater than in the other two gymnasts $(\mathrm{G} 2$ : $0.36 \mathrm{~m} / \mathrm{s}$; G3: $0.37 \mathrm{~m} / \mathrm{s}$ ).

In the consecutive instants of the back handspring (from $\mathrm{B}$ to $\mathrm{F}$ ), the values of the CoM horizontal velocity declined for each gymnast. One exception was gymnast Gl, for whom the velocity at the instant $\mathrm{D}$ was higher $(2.22 \mathrm{~m} / \mathrm{s})$ compared to the previous instant (C: $1.53 \mathrm{~m} / \mathrm{s})$.

The directions of the CoM in the vertical axis were the same in all instants denoted by the symbols B, C, E and F. The CoM moved downwards only in the point D for gymnasts G1 and G3 whereas in gymnast G2, it moved upwards.

Maximum values of the standard deviation (SD) for CoM velocities in the horizontal axis were obtained for individual athletes at different instants of the back handspring. The gymnast $\mathrm{Gl}$ obtained this value at the instant $\mathrm{E}(\mathrm{SD}=0.75 \mathrm{~m} / \mathrm{s})$, the gymnast $\mathrm{G} 2$ achieved it at the instant $\mathrm{D}(\mathrm{SD}=0.14 \mathrm{~m} / \mathrm{s})$, and the gymnast $\mathrm{G} 3$ obtained it at the instant $\mathrm{F}(\mathrm{SD}=0.53 \mathrm{~m} / \mathrm{s})$. In the case of the vertical velocity of the CoM, the maximum standard

Table 2. Horizontal and vertical velocity of the CoM at the boundaries between the back handspring phases $(\overline{\mathbf{x}} \pm \mathbf{S D})$

\begin{tabular}{|c|c|c|c|c|c|c|c|}
\hline \multirow{2}{*}{ Parameter } & \multirow{2}{*}{ Gymnast } & \multicolumn{5}{|c|}{ Boundaries between back handspring phases } \\
\cline { 2 - 7 } & & A & B & C & D & E & F \\
\hline \multirow{2}{*}{$\begin{array}{c}\text { Horizontal velocity of } \\
\text { CoM [m/s] }\end{array}$} & G1 & - & $1.95 \pm 0.56$ & $1.53 \pm 0.27$ & $2.22 \pm 0.15$ & $1.84 \pm 0.75$ & $1.04 \pm 0.40$ \\
\cline { 2 - 7 } & G2 & - & $1.55 \pm 0.03$ & $1.52 \pm 0.04$ & $1.36 \pm 0.14$ & $0.75 \pm 0.11$ & $0.36 \pm 0.10$ \\
\cline { 2 - 8 } & G3 & - & $2.18 \pm 0.30$ & $1.49 \pm 0.21$ & $1.20 \pm 0.14$ & $1.10 \pm 0.31$ & $0.37 \pm 0.53$ \\
\hline $\begin{array}{c}\text { Vertical velocity of } \\
\text { CoM [m/s] }\end{array}$ & G1 & - & $0.71 \pm 0.16$ & $-0.60 \pm 0.14$ & $-0.49 \pm 0.45$ & $-2.16 \pm 0.23$ & $3.42 \pm 0.21$ \\
\cline { 2 - 8 } & G2 & - & $1.01 \pm 0.12$ & $-0.60 \pm 0.09$ & $0.09 \pm 0.20$ & $-1.73 \pm 0.07$ & $3.40 \pm 0.12$ \\
\cline { 2 - 8 }
\end{tabular}


deviation was found in each athlete for the instant $\mathrm{D}$, with its values being $0.45 \mathrm{~m} / \mathrm{s}(\mathrm{Gl}), 0.20 \mathrm{~m} / \mathrm{s}$ (G2), and $0.43 \mathrm{~m} / \mathrm{s}$ (G3).

Table 3 shows the angular positions of the knee, hip, and shoulder joints at the boundaries between the back handspring phases.

At the boundary between the take-off and the first flight phase (B), the gymnast G2 had the most flexed knee joints. The value of this flexion (angle between the thigh and lower leg) was $136^{\circ}$, whereas in gymnasts G1 and G3, these values were $148^{\circ}$ and $146^{\circ}$, respectively. At the instant $C$, the value of the angular position in the knee joint in the gymnast G2 increased to $143^{\circ}$, whereas it decreased for the gymnasts G1 and G3 (by $116^{\circ}$ and $126^{\circ}$, respectively). As far as the moment of hand take-off (D) is concerned, the values observed in G1 and G2 were similar to extended knee joints $\left(178^{\circ}\right.$ and $\left.181^{\circ}\right)$, whereas in $\mathrm{G} 3$, insignificant flexion was found $\left(173^{\circ}\right)$.

At the end of the leg take-off (B) and in the beginning of upper limb support phase $(\mathrm{C})$, the gymnast Gl obtained the highest values of extension (angle between the trunk and thighs) in the hip joint (B: $153^{\circ}$; C: $136^{\circ}$ ). The same athlete was characterised by the lowest flexion of the hip joint at the instant $\mathrm{D}\left(212^{\circ}\right)$. As for the instants $\mathrm{E}$ and $\mathrm{F}$, this flexion was similar in the three gymnasts studied.
Maximum SD values for the angular positions of the knee joint occurred at the instant $C$ in all the gymnasts $\left(S D=5^{\circ}, 4^{\circ}\right.$, and $10^{\circ}$, respectively). The gymnast G2 also obtained the same value of SD $\left(4^{\circ}\right)$ at the instant E. Maximum SD values for the angular position of the hip joint were observed at the instant $\mathrm{D}$ $\left(\mathrm{SD}=6^{\circ}, 5^{\circ}\right.$, and $6^{\circ}$, respectively). However, maximum SD values for the angular position of the shoulder joint were recorded at different instants of the move: at the instants $\mathrm{C}$ and $\mathrm{F}$ for $\mathrm{Gl}$ $\left(7^{\circ}\right)$, at the instant $\mathrm{E}$ for $\mathrm{G} 2\left(4^{\circ}\right)$, and at the instant $\mathrm{D}$ for $\mathrm{G} 3\left(8^{\circ}\right)$.

Table 4 contains the results obtained for the angular velocity of the knee, hip, and shoulder joints.

The + or - signs for the angular velocity of the knee joint showed that the motion of extension occurred at the instants $B$ and $C$ and flexion was observed for the instant $E$ for all the athletes. At the instant D (during hand take-off), G1 and G3 extended their knee joints at the velocity of $224^{\circ} / \mathrm{s}$ (Gl) and $66^{\circ} / \mathrm{s}$ (G3), whereas G2 bent the knees at this moment with an insignificant velocity of $-2 \%$ s. Similarly, no similarities were found for the instant $\mathrm{F}$, where, after the toe take-off, the gymnasts Gl and G3 bent their knees at the velocity of $-225^{\circ} / \mathrm{s}$ (Gl) and $-86^{\circ} / \mathrm{s}(\mathrm{G} 3)$, whereas $\mathrm{G} 2$ extended the leg in this joint at $77^{\circ} / \mathrm{s}$.

The extension or bending of the hip joint was similar in the athletes at all the analysed instants except for F. At this mo-

Table 3. Angular position of the knee, hip, and shoulder joints at the boundaries between the back handspring phases ( $\overline{\mathbf{x}} \pm$ SD)

\begin{tabular}{|c|c|c|c|c|c|c|c|}
\hline \multirow{2}{*}{ Parameter } & \multirow{2}{*}{ Gymnast } & \multicolumn{6}{|c|}{ Boundaries between back handspring phases } \\
\hline & & A & B & C & D & $E$ & $F$ \\
\hline \multirow{3}{*}{$\begin{array}{l}\text { Angular position of } \\
\text { knee joint }\left[^{\circ}\right]\end{array}$} & G1 & $183 \pm 3$ & $148 \pm 4$ & $116 \pm 5$ & $178 \pm 2$ & $155 \pm 4$ & $188 \pm 3$ \\
\hline & G2 & $190 \pm 1$ & $136 \pm 1$ & $143 \pm 4$ & $181 \pm 1$ & $162 \pm 4$ & $183 \pm 2$ \\
\hline & G3 & $187 \pm 2$ & $146 \pm 3$ & $126 \pm 10$ & $173 \pm 1$ & $170 \pm 3$ & $182 \pm 3$ \\
\hline \multirow{3}{*}{$\begin{array}{l}\text { Angular position of hip } \\
\text { joint }\left[{ }^{\circ}\right]\end{array}$} & G1 & $170 \pm 3$ & $153 \pm 4$ & $136 \pm 4$ & $212 \pm 6$ & $249 \pm 3$ & $212 \pm 3$ \\
\hline & G2 & $168 \pm 2$ & $163 \pm 4$ & $148 \pm 2$ & $235 \pm 5$ & $248 \pm 2$ & $208 \pm 1$ \\
\hline & G3 & $166 \pm 3$ & $166 \pm 5$ & $149 \pm 3$ & $241 \pm 6$ & $247 \pm 3$ & $210 \pm 5$ \\
\hline \multirow{3}{*}{$\begin{array}{l}\text { Angular position of } \\
\text { shoulder joint }\left[{ }^{\circ}\right]\end{array}$} & $\mathrm{G} 1$ & $192 \pm 3$ & $172 \pm 5$ & $177 \pm 7$ & $223 \pm 3$ & $272 \pm 3$ & $245 \pm 7$ \\
\hline & G2 & $192 \pm 0$ & $188 \pm 1$ & $163 \pm 2$ & $210 \pm 2$ & $257 \pm 4$ & $208 \pm 2$ \\
\hline & G3 & $188 \pm 4$ & $182 \pm 4$ & $159 \pm 5$ & $215 \pm 8$ & $275 \pm 6$ & $241 \pm 5$ \\
\hline
\end{tabular}

Table 4. Angular velocity of the knee, hip, and shoulder joints at the boundaries between the back handspring phases $(\overline{\mathbf{x}} \pm$ SD)

\begin{tabular}{|c|c|c|c|c|c|c|c|}
\hline \multirow{2}{*}{ Parameter } & \multirow{2}{*}{ Gymnast } & \multicolumn{6}{|c|}{ Boundaries between back handspring phases } \\
\hline & & A & B & C & D & $E$ & $\mathbf{F}$ \\
\hline \multirow{3}{*}{$\begin{array}{l}\text { Angular velocity of } \\
\text { knee joint [\%/s] }\end{array}$} & G1 & - & $366 \pm 247$ & $291 \pm 334$ & $224 \pm 132$ & $-242 \pm 299$ & $-225 \pm 208$ \\
\hline & G2 & - & $402 \pm 69$ & $329 \pm 60$ & $-2 \pm 24$ & $-305 \pm 62$ & $77 \pm 163$ \\
\hline & G3 & - & $393 \pm 164$ & $166 \pm 249$ & $66 \pm 180$ & $-251 \pm 87$ & $-86 \pm 60$ \\
\hline \multirow{3}{*}{$\begin{array}{c}\text { Angular velocity of hip } \\
\text { joint }\left[{ }^{\circ} / \mathrm{s}\right]\end{array}$} & G1 & - & $-641 \pm 133$ & $204 \pm 149$ & $318 \pm 214$ & $-209 \pm 244$ & $128 \pm 94$ \\
\hline & G2 & - & $-661 \pm 25$ & $223 \pm 25$ & $407 \pm 19$ & $-437 \pm 43$ & $-57 \pm 69$ \\
\hline & G3 & - & $-580 \pm 101$ & $120 \pm 82$ & $431 \pm 83$ & $-220 \pm 117$ & $98 \pm 95$ \\
\hline \multirow{3}{*}{$\begin{array}{l}\text { Angular velocity of } \\
\text { shoulder joint }[\% / s]\end{array}$} & G1 & - & $-437 \pm 129$ & $325 \pm 152$ & $222 \pm 111$ & $-51 \pm 272$ & $-175 \pm 187$ \\
\hline & G2 & - & $-260 \pm 26$ & $272 \pm 33$ & $192 \pm 43$ & $-111 \pm 36$ & $-94 \pm 73$ \\
\hline & G3 & - & $-924 \pm 473$ & $168 \pm 86$ & $335 \pm 80$ & $-205 \pm 195$ & $-3 \pm 247$ \\
\hline
\end{tabular}


ment of the move, G1 an G3 extended their hip joints (G1: 128\% G3: $98 \%$ s), and G2 bent the hip joint at the angular velocity of $-57^{\circ} / \mathrm{s}$. In the case of the upper limbs, the same type of motion (flexion or extension) was recorded for the shoulder joint for all instants and all athletes.

At the beginning of the back handspring (at the instant B), the greatest values of angular velocity in the knee joint $\left(402^{\circ} / \mathrm{s}\right)$ and the hip joint $\left(-661^{\circ} / \mathrm{s}\right)$ were obtained by the athlete $\mathrm{G} 2$, whereas the highest values for the shoulder joint were achieved by G3 $\left(-924^{\circ} / \mathrm{s}\right)$.

In contrast to the other gymnasts, G2 was characterised by maximum SD values for angular velocity in all three joints at the instant F. This value was $163^{\circ} / \mathrm{s}$ for the knee joint, $69^{\circ} / \mathrm{s}$ for the hip joint, and $73^{\circ} \%$ for the shoulder joint.

Furthermore, maximum SD values in the Gl and G3 athletes for angular velocity in the knee joint were recorded at the instant $\mathrm{C}$ (Gl and G3: $\mathrm{SD}=334$ and $249^{\circ} / \mathrm{s}$, respectively), and those for angular velocity in the hip joint were obtained at the instant $\mathrm{E}$ (G1 and G3: SD = 244 and $117^{\circ} / \mathrm{s}$, respectively). The maximum value of standard deviation for angular velocity in the arm joint occurred at the instant $\mathrm{E}$ in the athlete $\mathrm{Gl}\left(\mathrm{SD}=272^{\circ} / \mathrm{s}\right)$ and at the instant $\mathrm{B}$ in $\mathrm{G} 3\left(\mathrm{SD}=473^{\circ} / \mathrm{s}\right)$.

\section{Discussion}

This study compared the back handspring technique performed by advanced artistic gymnasts. This comparison was made based on selected kinematic parameters with their values determined at the instants adopted as boundaries for individual phases.

CoM horizontal velocity decreased for all the instants of the move in all athletes. One exception was found for the gymnast with the longest training experience (G1) at the instant D. Higher CoM velocity at this instant of the move compared to the previous instant $(C)$ is likely to have been caused by knee extension in the upper limb support phase (C-D). As far as the beginning of this phase (the instant $C$ ) is concerned, the greatest knee flexion was found for the gymnast Gl. However, at the instant D, the value of the angular position of the knee joint in this athlete was similar to extended knees $\left(178^{\circ}\right)$. Furthermore, the difference in the angular velocities of the knee joint between the instants $C$ and D was the smallest in G1 $\left(67^{\circ} / \mathrm{s}\right)$, which caused the highest angular velocity in this joint to be maintained at the instant regarded as the final point for the upper limb support phase (D). It is remarkable that shoulder take-off also occurred in this phase, affecting the quality of performing the second phase of the flight and the quality of the take-off that started the acrobatic jump.

However, it should be emphasised that, except for the lower limb support phases, knee flexion during the back handspring is regarded as an error by judges [1]. Research previously conducted by the current authors [9, 13] and by other authors [11] has demonstrated that athletes bend their knees as early as in the first phase of flight. Therefore, it seems that maintaining extended knees would have an adverse effect on the parameters of the move which determine the quality of the elements performed after the back handspring.

Although the CoM vertical velocities were similar in the gymnasts at the final instant of the back handspring (F), a substantially higher velocity in the horizontal direction was observed for the gymnast with the longest training experience (G1). The study by Penitente et al. [12] also showed that at the final instant of the back handspring, female gymnasts at various levels of sports performance obtained similar CoM vertical values (the instant $\mathrm{E}$ in this study) and more varied values for the horizontal direction. The results of the present study also indicate that despite obtaining the highest CoM vertical velocity at the instant $\mathrm{B}$, the athlete with the shortest training experience (G3) did not sustain this advantage at the final take-off that completed the back handspring $(F)$. Maintaining specific biomechanical parameters during the performance of the back handspring is also likely to determine the level of performance of a technically complex acrobatic jump.

The analysis of angular position in the knee joint carried out in this study revealed that at the end of the leg take-off phase (B), this position was greater $\left(136^{\circ}\right.$ to $\left.148^{\circ}\right)$ than in the study by Ambroży et al. [11], compared to the position of both an acrobat $\left(110^{\circ}\right.$ to $\left.115^{\circ}\right)$ and a ju-jitsu athlete $\left(103^{\circ}\right.$ to $\left.109^{\circ}\right)$. For the same moment of the move, lower values of angular position were found for the hip joint in the present study $\left(153^{\circ}\right.$ to $\left.166^{\circ}\right)$ compared to the results presented by the above authors both for the acrobat $\left(196^{\circ}\right.$ to $\left.199^{\circ}\right)$ and the ju-jitsu athlete $\left(202^{\circ}\right.$ to $205^{\circ}$ ). The greater flexion in the knee joint and lower flexion in the hip joint meant that the athletes in our study took off more backwards than upwards compared to the two athletes cited in the above study. It is remarkable that the greatest upward takeoff was observed for the ju-jitsu athlete, followed by the acrobat and that the greatest backward take-off was found for the three artistic gymnasts analysed in this study (even with hyperextension in the hip joints ranging from $14^{\circ}$ to $27^{\circ}$ ).

The shoulder joint flexion at the end of the hand take-off (D) recorded for the gymnast with the longest training experience $\left(223^{\circ}\right)$ was similar to that of the ju-jitsu athlete $\left(221^{\circ}\right.$ to $230^{\circ}$ ) from Ambroży et al.'s study [11] and greater than those of the other artistic gymnasts in the current study $\left(210^{\circ}\right.$ to $\left.215^{\circ}\right)$ and of the acrobat in the study cited $\left(193^{\circ}\right.$ to $\left.196^{\circ}\right)$. The bigger flexion in the arm joint pointed to greater body inclination in this phase of the move. However, a comparison of the value of flexion in all the athletes did not show the effect of training experience on this parameter.

In terms of the angular velocities of the three joints analysed, the biggest variation of the results was found for the shoulder joint at the instant that completed the lower limb takeoff (B). The biggest angular velocity in this joint was obtained by the G3 athlete, and the lowest value was found for G2 (the difference between them was $664^{\circ} / \mathrm{s}$ ). However, at each analysed instant of the back handspring, the direction of shoulder work (flexion and extension) was the same in all the athletes.

Sforza et al. $[6,14]$ have used the obtained values of standard deviations to interpret movement repeatability. Standard deviations calculated for the CoM vertical and horizontal velocities pointed to the best repeatability of these parameters in G2. This gymnast obtained the lowest SD values of all the three athletes. A lower SD value was only found for the gymnast G3, who had a two times lower standard deviation of CoM vertical velocity recorded at the instant $F$ compared to G2. With respect to angular positions, the values of standard deviations for the three analysed joints were small for all the athletes. The maximum $\mathrm{SD}$ value was found for the angular position in the knee joint at the instant $C$ in the athlete with the shortest training experience (G3). The biggest repeatability of these parameters was also observed for the athlete with 16 years of training experience (G2); another gymnast obtained smaller SD values only in two cases at the instant E: for the angular positions of the knee joint and shoulder joint. The best repeatability of angular velocities was also found for G2 at each instant of the move. Only the repeatability of angular velocity in the knee joint at the instant F was found to be better for G3. The fact that more favourable results in terms of standard deviation were found for the gymnast G2 
and the gymnast G3 compared to the gymnast with the longest training experience suggests that it is likely that, at a certain stage of training, the level of repeatability of the move is affected by factors other than the years of training.

For artistic gymnasts with many years of training experience, the back handspring is a relatively easy move which they perform repeatedly. However, the results obtained in this study demonstrated both similarities and substantial differences in the technique of performing the back handspring. In most of the cases, the directions of linear CoM velocities and angular velocities were similar in the joints analysed. Very similar values were also obtained for angular positions (particularly at the instants $A$ for all joints, $\mathrm{E}$ for the hip joint, and $\mathrm{F}$ for the knee and hip joints). Furthermore, the values which turned out to be more varied in the athletes concerned angular velocities (particularly at the instant B for the shoulder joint).

\section{Conclusions}

1. According to the coaches (judges) and based on a comparison of the values of kinematic parameters, all the athletes who participated in the study had a similarly high technical level.

2. The most substantial differences between athletes were found in the values of the horizontal velocity of the CoM at the end of back handspring. The athlete with the longest training experience achieved values which were three times higher than those obtained by the other two athletes with shorter experience.

3. Horizontal CoM velocity at the end of the back handspring declined for all the gymnasts, with the smallest decrease observed for the athlete with the longest training experience and the biggest one found for the athlete with the shortest training experience.

4. Vertical CoM velocity increased in the consecutive phases of the back handspring in all the athletes and was the biggest for the athlete with the longest training experience and the lowest for the athlete with the shortest training experience.

5. Angular position in the knee, hip, and shoulder joints at the boundaries of the back handspring phases showed small standard deviations in all the athletes $\left(0^{\circ}<\mathrm{SD}<10^{\circ}\right)$, which suggests high repeatability of the move in these terms.

6. Angular velocity in the knee, hip, and shoulder joints at the boundaries of the back handspring phases obtained during flexion and extension showed high standard deviations in all the athletes $\left(19^{\circ} / \mathrm{s}<\mathrm{SD}<473^{\circ} / \mathrm{s}\right)$, which suggests high variability among the kinematic parameters.

\section{Acknowledgements}

The study was financed from Polish budgetary resources for science allocated to the University School of Physical Education in Kraków in the year 2015 under Grant No. 81/BS/IS/2015 by the Ministry of Science and Higher Education.

\section{Literature}

1. Federation International de Gymnastique (FIG). (2013). Code of points. Artistic gymnastics for men. Switzerland: FIG.

2. Sands W.A., McNeal J.R. (2006). Hand position in a back handspring (flic-flac). Technique 26, 8-9.

3. Farana R., Jandacka D., Irwin G. (2013). Influence of different hand positions on impact forces and elbow loading during the round off in gymnastics: A case study. Science of Gymnastics Journal 5(2), 5-9.

4. Arkaev L., Suczilin N. (2004). Gymnastics - how to create champions. Moscow: FiS.

5. Raczek J., Król H., Bacik B. (1994). Research aimed at determining objective criteria for the analysis and assessment of movement. Part 1 - constancy. Antropomotoryka 11, 77-89. [in Polish]

6. Sforza Ch., Turci M., Grassi G.P., Shirai Y.F., Pizzini G., Ferrario V.F. (2002). Repeatability of mae-geri-keage in traditional karate: A three-dimensional analysis with blackbelt karateka. Perceptual \& Motor Skills 95(2), 433-445.

7. Kochanowicz K., Boraczyńska L.B., Boraczyński T. (2009). Quantitative and qualitative evaluation of motor coordination abilities in gymnast girls aged 7-9 years. Baltic Journal of Health and Physical Activity 1(1), 62-69.

8. Dowdell T. (2010). Characteristics of effective gymnastics coaching. Science of Gymnastics Journal 2(1), 15-23.

9. Omorczyk J., Nosiadek L., Nosiadek A., Chwała W. (2014). Use of biomechanical analysis for technical training in artistic gymnastics using the example of a back handspring. In Cz. Urbanik, A. Mastalerz, D. Iwańska (eds.), Selected problems of biomechanics of sport and rehabilitation (pp. 105115). Warszawa: AWF.

10. Prassas S., Young-Hoo K., Sands W.A. (2006). Biomechanical research in artistic gymnastics: A review. Sports Biomechecanics 5(2), 261-291.

11. Ambroży T., Chwała W., Ambroży D., Latinek K. (2010). Three-dimensional analysis as an example of an objective assessment system of the technique in gymnastics, on the basis of the back handspring. In T. Ambroży, D. Ambroży (eds.), Traditional and modern forms of dance and gymnastics from the perspective of physical culture (pp. 240-256). Kraków: AWF.

12. Penitente G., Merni F., Sands A. (2011). Kinematic analysis of the centre of mass in the back handspring: A case study. Gym Coach 4, 1-11.

13. Omorczyk J., Nosiadek L., Ambroży T., Nosiadek A. (2015). High-frequency video capture and a computer program with frame-by-frame angle determination functionality as tools that support judging in artistic gymnastics. Acta of Bioengineering \& Biomechanics 17(3), 85-93.

14. Sforza Ch., Turci M., Grassi G.P., Fragnito N., Serrao G., Ferrario V.F. (2001). Repeatability of choku-tsuki and oitsuki in Shotokan karate: A 3-dimensional analysis with thirteen black-belt karateka. Pereceptual \& Motor Skills 92, 1230-1232.

Submitted: March 23, 2017

Accepted: May 23, 2017 